\title{
Makroalgae di Paparan Terumbu Karang Kepulauan Anambas
}

\author{
Achmad Kadi \\ Pusat Penelitian Oseanolog-LIPI, JI. Pasir Putih I No.1 Ancol Timur, Jakarta-Utara. \\ Diterima 20-07-2008 Disetujui 03-08-2009
}

\begin{abstract}
Macroalgae research in Anambas Islands that is the reef flats Jemaja, Pemutus and Matak Waters was carried on June 2005. Survey method on the research using quadrat transect. Macroalgae is a marine flora which contains Chlorophyceae, Phaeophyceae and Rhodophyceae. Biodiversity in the research location was 18 species. The higher diversity index $(\mathrm{H})$ was 0.24 and equitability index (e) was 0,105 . The higher density of species were 207 individuals. Dominant species was $22,83 \%$ by Sargassum polycystum.
\end{abstract}

Keywords: Biodiversity, density, dominance, macroalgae, Anambas.

\section{PENDAHULUAN}

Makroalgae adalah salah satu flora yang hidup dalam air laut, kehadirannya dapat dijumpai di paparan terumbu karang Perairan pantai Kepulauan Anambas

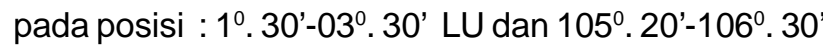
BT. Makroalgae di paparan terumbu karang dapat dipengaruhi oleh beberapa factor antara lain faktor abiotik dan biotik. Pengaruh faktor abiotik di perairan Kepulauan Anambas belum terjadi pencemaran air, faktor biotik umum dilakukan oleh pemangsa dan kompetitor. Pemangsa makroalgaa dimakan oleh ikanikan yang bersifat herbivore (Round, 1980). Kompetisi makroalgae dengan biota karang dilakukan dalam perolehan zat hara pada ruang tumbuh yang sama (Nybakken, 1992). Arthur, (1972), menyatakan bahwa kompleksitas habitat berpengaruh terhadap kelimpahan dan keragaman jenis. Substrat dasar makroalgae yang utama yakni pasir, pecahan karang, karang mati, dan batu karang.

Penelitian makroalgae ini masih terbatas pada keragaman, kepadatan dan dominasi makroalgae di paparan terumbu karang Kepulauan Anambas. Perairan Pantai masih sangat ideal untuk penelitian, karena jauh sumber pencemaran dan pemukiman penduduk. Faktor lingkungan perairan pantai yang stabil sangat dibutuhkan dalam memperoleh keragaman, kepadatan dan dominasi jenis makroalgae. Menurut Connel, (1974), menyatakan suatu lingkungan perairan dalam kondisi stabil akan menunjukan jumlah individu yang seimbang

*Telp: 021- 64713850, Fax: 021- 64711948

Email: - dari semua spesies yang ada, sebaliknya suatu lingkungan perairan yang berubah-ubah akan menyebabkan penyebaran jenis rendah dan cenderung ada individu yang dominan. Kehadiran jenis makroalgae di perairan pantai Kepulauan Anambas sangat penting yakni ikut dalam pembentukan ekosistem terumbu karang sebagai tempat berlindung biota-biota kecil sebagai daerah asuhan benih ikan dan udang. Dawson, (1966), menyatakan peran lain makroalgae diperoleh dari maraga Calcareous kandungan kalsit dan aragonit dapat membentuk semen sebagai perekat pecahan karang mati yang berguna untuk ketahanan terhadap benturan ombak besar.

Penelitian keragaman, kepadatan dan dominasi makroalgae ini masih jarang dilakukan di Kepulauan anambas. Topik yang sama banyak dilakukan di daerah subtropik (Allison, 2004). Hal ini pula yang menjadi pertimbangan untuk melengkapi data makroalgae tentang keragaman, kepadatan, dan dominasi yang dilakukan di perairan dalam kondisi biofisik yang berbeda. Di Indonesia data Keragaman, kepadatan makroalgae belum terpola di beberapa perairan Pulau kecil maupun besar, karena kehadiran makroalgae di beberapa perairan masih banyak yang belum teridentifikasi.

Makalah disajikan dalam bentuk data dan informasi mengenai keragaman, kepadatan dan jenis makroalgae yang dominan di perairan Pulau Jemaja, Pumutus dan Mantak. Diharapkan dapat memberikan gambaran sebagian kekayaan makroalgae di Kepulauan Anambas. 


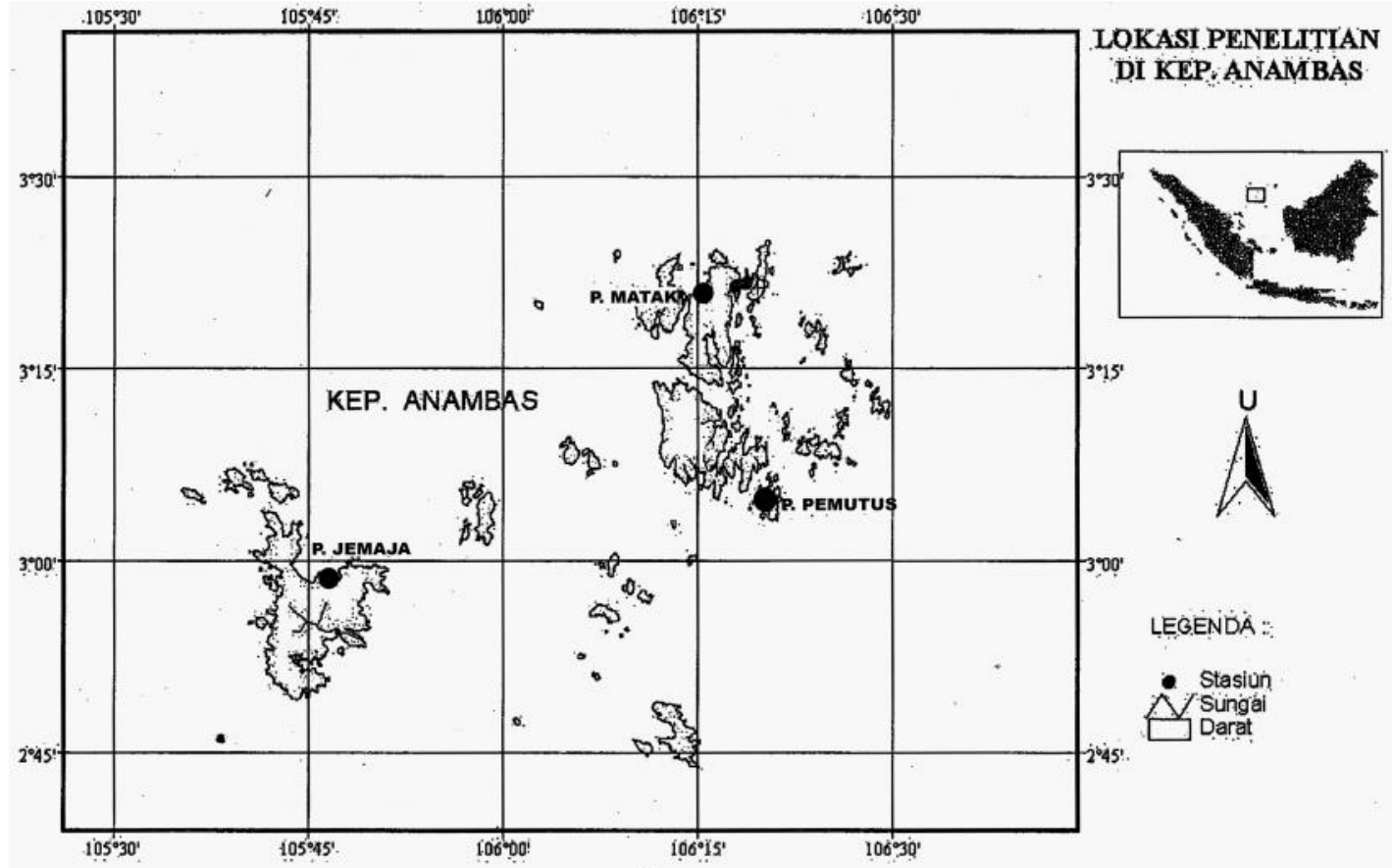

Gambar 1. Lokasi Penelitian di Kepulauan Anambas

\section{BAHAN DAN METODE}

Penelitian makroalgae di perairan pantai paparan terumbu karang di Pulau-Pulau Kepulauan Anambas dilaksanakan pada bulan Juni tahun 2005. Data lapangan diperoleh dari pencatatan hasil sampel penelitian. Metode dengan survey menggunakan transek kuadrat di masing-masing stasiun ditarik garis tegak lurus pantai ke arah tubir. Setiap10 m diplot dengan frame alumunium $1 \times 1 \mathrm{~m}^{2}$ diambil sampelnya dan masing-masing spesies dihitung individunya per bonggol (holdfast). Penamaan jenis makroalgae diidentifikasi berdasarkan Taylor (1967) dan Trono \& Fortez (1988). Keragaman jumlah jenis dan individu dalam $1 \mathrm{~m}^{2}$ dihitung menggunakan rumus Shannon (1948) dengan indeks Keragaman (H). Kemerataan jenis menurut Pielou (1966) untuk mendapakan indek kemerataan (e)sebagai berikut:

$$
\text { 1. } H=-\sum_{i=1}^{s}\left[\frac{(n i)}{(n)} \operatorname{Ln} \frac{(n i)}{(n)}\right]
$$

$\mathrm{H}=$ Shannon indeks; $\mathrm{n}=$ Jumlah jenis; $\mathrm{ni}=$ jumlah total sampel individu ke-i.

2. $e=H / \log s$

$\mathrm{e}=$ indeks kemerataan; $\mathrm{s}=$ jumlah jenis

\section{HASIL DAN PEMBAHASAN}

Diskripsi umum. Keragaman jenis makroalgae diseluruh paparan terumbu karang Kepulauan Anambas diperoleh dengan jumlah total makroalgae 18 jenis. Nilai keragaman tertinggi 0,240, kemerataan 0,104, kepadatan jenis tertinggi 207 individu dan jenis dominan $21,73 \%$. Keragaman jenis makroalgae sebagai pembanding dijumpai pula di perairan Kepulauan Bangka diperoleh dengan jumlah total 30 jenis, indeks keragaman tertinggi 0.230 , kemerataan 0,022 , kepadatan jenis 230 individu dan jenis dominan 24,1\% (Kadi, 2005). Di Kepulauan Seribu tercatat 101 jenis dan jenis dominan $14,41 \%$ (Atmadja \& Sulistijo 1980). Perairan Indonesia dan Malaysia keragaman makroalgae diperoleh 10-14 jenis (Grevo, 2004; Wong \& Phang, 2004). Penelitian makroalgae seluruh Indonesia terdahulu melalui ekspedisi Siboga tahun 1888-1889 tercatat 555 jenis (Bosse, 1928).

Paparan terumbu karang secara umum Perairan Kepulauan Anambas (Gambar 1) terbentuk paparan terumbu (reef plats), punggung terumbu (ridge) dan lereng terumbu (reef slope). Subtrat dasar paparan terumbu terdiri dari pasir, gravel, batu karang dan karang mati. Makroalgae yang diperoleh Caulerpa, Halimeda, Sargassum, Turbinaria, Gracilaria, Neomeris, dan Dictyosphaeria. Di daerah punggung terumbu bagian lereng dalam sebagai habitat makroalgae Sargassum, Turbinaria, Halimeda dan Gracilaria. Daerah punggung terumbu bagian lereng luar atau disebut tubir diperoleh marga Calcareous algae sebagai makroalgae berkapur.

Pulau Jemaja. Posisi: 02. 58'. 51" LU-105. 46'. 78"BT. Paparan terumbu karang dengan lebar dari garis 
Tabel 1. Makroalgae di paparan terumbu karang Kepulauan Anambas

\begin{tabular}{lccc}
\hline Nama makroalgae & Stasiun 1 (P.Jemaja) & Stasiun 2 (P.Pemutus) & Stasiun 3 (P. Matak) \\
\hline Chlorophyceae & 30 & - & 21 \\
Caulerpa racemosa & 12 & - & - \\
Caulerpa sertularoides & 15 & 5 & - \\
Caulerpa serrulata & 9 & 9 & - \\
Dyctiosphaerica cavernosa & 20 & - & - \\
Halimeda macroloba & - & - & 22 \\
Halimeda opuntia & - & - & 15 \\
Neomeris annulata & & & - \\
Phaeophyceae & - & 8 & 7 \\
Dyctyota dichotoma & - & 12 & - \\
Hormophysa triquetra & 11 & 17 & 13 \\
Padina australis & - & 26 & - \\
Sargassum echinocarpum & 35 & 37 & 8 \\
Sargassum polycystum & - & 7 & 25 \\
Turbinaria ornata & & & - \\
Rhodophyceae & 30 & - & 21 \\
Eucheuma spinosum & 45 & - & 7 \\
Gracilaria coronopifolia & - & 36 & - \\
Gracilaria salicornia & - & - & 9 \\
Hypnea cervicornis & - & 5 & 139 \\
Hypnea musciformis & 9 & 10 & 0,231 \\
Jumlah jenis & 207 & 162 & 0,105 \\
Jumlah individu & 0,219 & 0,240 & 04104 \\
Indeks keragaman $(\mathrm{H})$ & 0,100 & & \\
Indeks kemerataan $(\mathrm{e})$ & & & \\
\hline
\end{tabular}

Tabel 2. Substrat dasar di paparan terumbu karang Kepulauan Anambas (\%)

\begin{tabular}{lccc}
\hline Jenis substrat dasar & Stasiun 1 (P. Jemaja) & Stasiun 2 (P. Pemutus) & Stasiun 3 (P. Matak) \\
\hline 1. Pasir & 5 & 5 & 10 \\
2. Batu karang & 45 & 45 & 35 \\
3. Karang mati & 10 & 20 & 10 \\
4. Karang hidup (di bibir tubir) & 40 & 30 & 45 \\
\hline
\end{tabular}

pantai ke arah tubir $250 \mathrm{~m}$ dan kedalaman paparan terumbu surut terendah mencapai $50 \mathrm{~cm}$. Substrat dasar paparan terumbu karang terdiri dari pasir, batu karang, dan karang mati. Substrat pasir dan batu karang berada di cekungan paparan terumbu diperoleh makroalgae Caulerpa dan Halimeda. Makroalgae di daerah tubir marga Sargassum mengelilingi sepanjang bibir tubir. Makroalgae di paparan terumbu karang berjumlah 9 jenis dari kelas Chlorophyceae 5 jenis, Phaeophyceae 2 jenis dan Rhodophyceae 2 jenis (Tabel 1 dan 2).

Pulau Pemutus. Posisi : 03․ 04'. 84" LU-106. 19'. 86" BT. Perairan pantai bekas abrasi daratan pantai tersambung membentuk terusan (channel) dengan pantai lain. Pantai dengan lebar bentangan dari garis pantai ke tubir $150 \mathrm{~m}$ dan kedalaman paparan terumbu surut teredah mencapai $50 \mathrm{~cm}$. Paparan terumbu karang terbentuk substrat dasar dari pasir, batu karang dan karang mati. Substrat pasir dan batu karang banyak diperoleh Caulerpa dan Dictyosphaeria, sedangkan substrat karang mati diperoleh Hormophysa, Padina,
Sargassum dan Turbinaria. Makroalgae Sargassum dijumpai pula di daerah tubir. Makroalgae di paparan terumbu karang berjumlah 10 jenis dari kelas Chlorophyceae 2 jenis, Phaeophyceae 6 jenis dan Rhodophyceae 2 jenis. (Tabel 1 dan 2).

Pulau Matak. Posisi : 03․ 21'. 37" LU-106'. 17'. 99" BT. Rataan terumbu karang dengan bentangan lebar dari garis pantai ke arah tubir $150 \mathrm{~m}$, kedalaman air waktu pasang surut terendah $50 \mathrm{~cm}$. Paparan terumbu pada waktu surut terendah saling berhubungan dengan paparan terumbu Pulau-pulau kecil disekitarnya. Lereng punggung terumbu bagian dalam terdapat cekungan ke arah daratan pantai. Daerah tepi pantai terdapat hutan mangrove. Substrat terbentuk dari pasir dan karang mati. Makroalgae meliputi Caulerpa, Neomeris, Halimeda, Hormophysa, Turbinaria, Eucheuma, Gracilaria, Hypnea dan Sargassum. Di daerah tubir diperoleh Sargassum di sepanjang bibir tubir. Makroalgae di seluruh paparan terumbu berjumlah 9 jenis dari kelas Chlorophyceae 3 jenis, Phaeophyceae 3 jenis dan Rhodophyceae 3 jenis (Tabel 1dan 2). 


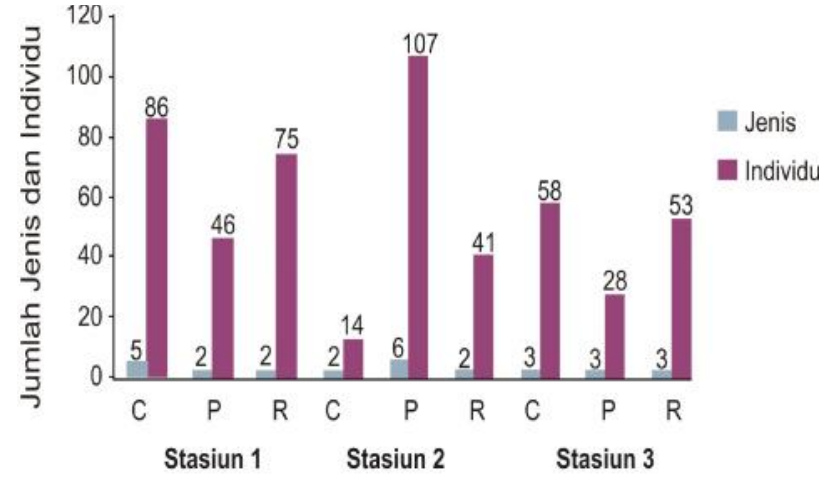

Keterangan: $\mathrm{C}=$ Chlorophyta, $\mathrm{P}=$ Phaeophyta dan $\mathrm{R}=$ Rhodophyta

Gambar 2. Keragaman makroalgae di Kepulauan Anambas

Keragaman makroalgae. Makroalgae Kepulauan Anambas diperoleh jumlah total 18 jenis. Kelas Chlorophyceae 7 jenis, Phaeophyceae 6 jenis dan Rhodophyceae 5 jenis. Keragaman Pulau Jemaja diperoleh indeks keragaman nilai 0,219 dan kemerataan 0,100 . Pulau Jemaja. diperoleh indeks keragaman 0,240 dan kemerataan 0,104. Pulau Matak indeks keragaman 0,231 dan kemerataan 0,105. Indeks keragaman tertinggi diperoleh di Pulau Pemutus 0,105. Indeks kemertaan tertinggi diperoleh di Matak 0.105 (Gambar 2 dan 3). Sebagai pembanding dalam deretan Kepulauan Batam seperti Pulau Dedap, Pengelap, Abang Besar, dan Abang Kecil kehadiran makroalgae mencapai jumlah 13, 18, 26 dan 5 jenis, indeks keragaman tertinggi 0,235 dan kemerataan 0,146 berada di Pulau Abang Kecil (Kadi, 2006).

Kehadiran dan keragaman jenis di Kepulauan Anambas dan Batam mempunyai jumlah dan keragaman jenis yang sama tinggi. Menurut Liao et al., (2004), dalam Expedisi Kepulauan Anambas tahun 2002 diseluruh Pulau besar dan kecil diperoleh 74 jenis. Kepulauan Anambas pada bulan Juni tahun 2005 musim panen makroalgae alami yang berpengaruh pada jumlah jenis lebih rendah, karena terjadi pelepaskan thallus dari holfastnya. Kehadiran jenis makroalgae masih dalam bentuk pertumbuhan benih belum seluruhnya teridentifikasi. Jumlah keragaman jenis sangat dipengaruhi oleh banyaknya kehadiran dan individu makroalgae yang ada di paparan terumbu karang (Grevo, 2004).

Kepadatan dan dominasi. Makroalgae Kepulauan Anambas diseluruh paparan terumbu karang diperoleh 18 jenis dan 508 individu. Kepadatan makroalgae Pulau Jemaja menunjukan Chlorophyceae 5 jenis dan 86 individu, Phaeophyceae 2 jenis dan 46 individu,

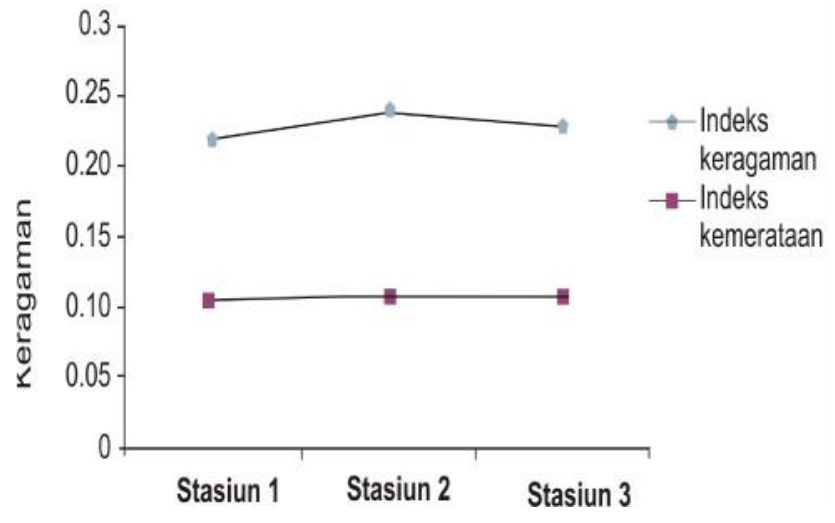

Gambar 3. Indeks keragaman dan Indeks kemerataan jenis makroalgae di Kepulauan Anambas

Rhodophyceae 2 jenis dan 75 individu. serta Jenis yang dominan Gracilaria coronopifolia 21,75\%. Kepadatan makroalgae Pulau Pemutus Chlorophyceae 2 jenis dan 14 individu, Phaeophyceae 6 jenis dan 107 individu., Rhodophyceae 2 jenis 41 individu serta jenis yang dominan Sargassum polycystum $22,83 \%$. Kepadatan Pulau Matak Chlorophyseae 3 jenis dan 58 individu, Phaeophyceae 3 jenis dan 28 individu, Rhodophyceae 3 jenis 53 individu serta jenis dominan Eucheuma spinosum $17,98 \%$.

Kepadatan tertinggi diperoleh Phaeophyceae 107 individu berada di Pulau Jemaja. Jenis yang dominan di Pulau Pemutus Sargassum polycystum 22,83\%. Substrat dasar paparan terumbu karang masing-masing pulau berbeda. Substrat batu karang Pulau Jemaja dan Pemutus diperoleh jumlah tertinggi kehadiran jenis dan individu makroalgae (Tabel 2). Menurut Wong dan Phang (2004) menyatakan bahwa kepadatan makroalgae sangat dipengaruhi oleh pergantian musim dan kondisi substrat dasar paparan terumbu yang labil dan cenderung akan menyebabkan penyebaran jenis rendah serta adanya individu yang dominan. Kepadatan jenis diperoleh pula di Pulau Bangka Chlorophyta 120 individu, Phaeophyta 122 individu dan Rhodophyta 129 individu dengan jenis dominan Gracilaria coronopifolia $23,5 \%$, apabila kepadatan dan jenis yang dominan dibandingkan maka lebih tinggi daripada di Kepulauan Anambas (Kadi, 2005).

\section{KESIMPULAN}

Jumlah total makroalgae di Kepulauan Anambas diperoleh 18 jenis tertinggi berada di Pulau Pemutus terdapat 10 jenis. Keragaman jenis $(\mathrm{H})$ tertinggi di paparan terumbu karang berada di Pulau Pemutus dengan indeks keragaman 0,240. Kemerataan jenis 
tertinggi di Pulau Matak diperoleh indeks kemerataan (e) 0,105. Kepadatan tertinggi berada di Pulau Jemaja diperoleh 207 individu dengan dominasi jenis berada di Pulau Pemutus diduduki oleh Sargassum polycystum $22,83 \%$.

\section{UCAPAN TERIMA KASIH}

Penelitian ini dibiayai oleh Pusat Penelitian Oseanografi-LIPI, Jakarta. Terima kasih disampaikan kepada Tim Ekspedisi Baruna Jaya VII, teknisi Subagya Wijaya dan rekan-rekan peneliti yang ikut terlibat dalam penelitian ini atas kerja samanya.

\section{DAFTAR PUSTAKA}

Arthur, M.R.H. 1972. Geographycal, Ecology, Pattern in the distribution of species. New York, Happer \& Row, Publ. Halaman 269

Atmadja, W.S. \& Sulistijo. 1980. Algae bentik. Di dalam: Moosa M.K., Kastoro, W. \& Romimohtarto, K. (eds.). Peta Sebaran geografik. Beberapa biota laut perairan Indonesia. Jakarta: Lembaga Oseanologi Nasional-LIPI. Halaman 42-51.

Bosse, A.W.V. 1928. Liste des algues du Siboga Rhodophyceae traisimi partie Gigartinales et Rhodymeniales. Siboga Expeditie LIXd. Leiden, E.J.Brill. Halaman 533.

Connel, Y.H. 1974. Field experiment in marine ecology. Di dalam Richard, N. \& Mariscal (eds.). New York: Academy Press.

Dawson, Y.E. 1966. Marine Botany: An introduction. Musium, Smithsonian Institution United States Nasional. Halaman 234
Makroalgae Di Paparan Terumbu Karang

Grevo, S.G. 2004. Biodiversity of Indonesian seaweeds. Di dalam Phang, S.M., Ching, C.V., Chye, H.S., Mokhtar, N.H., \& Sim, J.O.L. (editor). Marine Science into the Millenium, New Perspectives and Challenges. Proceeding of the AsiaPacific Conference on Marine Science \& Technology. Kuala Lumpur. Halaman 47-54.

Kadi, A. 2005. Makroalgae di Perairan Kepulauan Bangka, Belitung dan Karimata. Jour. Mar. Sci. Univ. Diponegoro 10: 98-105

Kadi, A. 2006. Struktur komunitas makroalgae di Pulau Pengelap, Dedap, Abang Besar dan Abang Kecil Kepulauan Riau. Jour. Mar. Sci. Univ. Diponegoro 11: 234-240.

Liao, L.M., Uy, F.A., \& Heyrosa, N.A. 2004. Macrobenthic Marine Algae and Seagrasses of the Anambas Expedition 2002. The Reff. Bul. of Zol. 2004 Sup. 1: 19-23.

Nybakken, J.W. 1992. Biologi Laut: Suatu pendekatan ekologis. Terjemahan M. Eidman. Jakarta: Gramedia Pustaka Utama.

Pielou, C. E. 1966. The measurement of diversity in different types of biological collections. Jour. Theor. Biol. 13: 131144.

Round, F.E. 1980. The Ecology of Algae. London: Cambridge University Press.

Shannon, C.E. 1948. A mathematical theory of communication Bull. Syst. The. Jour. 27: 379-423.

Taylor, W.R. 1967. Marine algae of Eaestern tropical and subtropical coast of the America. Univ. Micigan. Press. XXI: 870.

Trono, G.C. Jr. \& Fortez, E.T. 1988. Philippine Seaweeds. Manila: National book store,Inc.Metro. Halaman 330.

Wong, C.L. \& Phang, S.M. 2004. Diversity and distribution of Malaysian Sargassum sp. Di dalam: Phang, S.M., Ching, C.V., Chye, H.S., Mohktar, N.H., \& Sim, J.O.L. (Editor.). Proceeding of the Asia-Pacific Conference on Marine Science \& Technology. Kuala Lumpur. Halaman 23-46 